Technical Note

\title{
A guideline for sample preparation in modern tree-ring stable isotope research
}

\author{
Karina Schollaen ${ }^{\mathrm{a}, \mathrm{b}, \mathrm{c}, *}$, Heiko Baschek $^{\mathrm{d}}$, Ingo Heinrich ${ }^{\mathrm{a}}$, Franziska Slotta ${ }^{\mathrm{a}, \mathrm{e}}$, Maren Pauly ${ }^{\mathrm{a}}$, \\ Gerhard Helle, \\ a German Centre for GeoSciences - GFZ-, Section 5.2 Climate Dynamics and Landscape Evolution, Potsdam, Germany \\ ${ }^{\mathrm{b}}$ Alfred Wegener Institute Helmholtz Centre for Polar and Marine Research, Research Section Potsdam, Germany \\ ${ }^{c}$ Potsdam Institute for Climate Impact Research, Research Domain 2 - Climate Impacts and Vulnerabilities, Potsdam, Germany \\ d Monumentenstraße 3, 10829 Berlin, Germany \\ e Freie Universität Berlin, Institute of Geological Sciences, Section Palaeontology, Berlin, Germany
}

A R T I C L E I N F O

\section{Keywords:}

Tree rings

Stable isotopes

Wood cross section

Cellulose extraction

Homogenization

High-throughput IRMS

UV-laser microdissection

Dendrochronology

African baobab (Adansonia spp.)

Teak (Tectona grandis)

\begin{abstract}
A B S T R A C T
The comprehensive procedure of wood sample preparation, including tree-ring dissection, cellulose extraction, homogenization and packing for stable isotope analysis, is labour intensive and time consuming.

Based on a brief compilation of existing methods, we present a methodological approach from pre-analyses considerations to wood sample preparation, semi-automated chemical extraction of cellulose from tree-ring cross-sections, and tree-ring dissection for stable isotope ratio mass spectrometry: the Cross-Section Extraction and Dissection (CSED) guideline. Following the CSED guideline can considerably increase efficiency of tree-ring stable isotope measurement compared to classical methods $<$ ABS-P $>$ We introduce a user-friendly device for cellulose extraction, allowing simultaneous treatment of wood cross-sections of a total length of $180 \mathrm{~cm}$ (equivalent to 6 increment cores of $30 \mathrm{~cm}$ length) and thickness of $0.6-2.0 \mathrm{~mm}$. After cellulose extraction, treering structures of 10 tree species (coniferous and angiosperm wood) with different wood growth rates and treering boundaries, largely remained well identifiable.

Further, we demonstrate that tree rings from cellulose cross-sections can be dissected at annual to intraseasonal resolution, utilizing simple manual devices as well as sophisticated UV-laser microdissection microscopes in a way that sample homogenization is no longer necessary in most cases.

We investigate seasonal precipitation signals in high-resolution intra-annual $\delta^{18} \mathrm{O}$ cellulose values from African baobab, performed by using UV-laser microdissection microscopes.
\end{abstract}

\section{Introduction}

Tree-ring stable isotope records are powerful proxies in palaeoclimatic (e.g. Brienen et al., 2012; Heinrich et al., 2013; Konter et al., 2014; Loader et al., 2010; Treydte et al., 2006) and plant physiological studies (e.g. Gessler et al., 2013; Helle and Schleser, 2004; Simard et al., 2012). Different wood components (wood, lignin or cellulose) can be used in the analysis of carbon, oxygen or hydrogen stable isotopes. Cellulose, a primary carbohydrate, is often the preferred sample material because of its short synthesis pathway, singular chemical composition and physical immobility within the stem (McCarroll and Loader, 2004).

Recent advancements in the methodology of tree-ring stable isotope analysis have permitted the efficient measurement of a large number of samples using minimal sample amounts (few micrograms) (Gori et al., 2013; Kornexl et al., 1999; Koziet, 1997; Loader et al., 2014; Saurer et al., 1998). However, such analytical developments complicate sample preparation, as they require very high sample purity and homogeneity. Furthermore, tree-ring dissection and chemical preparation (cellulose extraction from wood tissue) are time consuming, prompting research into improving the efficiency of these procedures for stable isotope analysis (Anchukaitis et al., 2008; Brendel et al., 2000; Cullen and MacFarlane, 2005; Gaudinski et al., 2005; Green, 1963; Harada et al., 2014; Hook et al., 2015; Laumer et al., 2009; Leavitt, 2010; Leavitt and Danzer, 1993; Loader et al., 1997; Rinne et al., 2005; Sheu and Chiu, 1995; Wieloch et al., 2011). As indicated in the overview of key procedures of tree-ring stable isotope analysis (Fig. 1), all of these approaches start with sampling tree rings by using

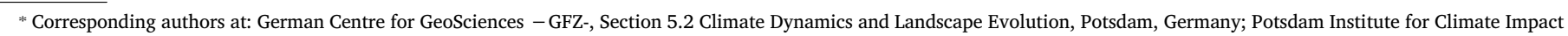
Research, Research Domain 2 - Climate Impacts and Vulnerabilities, Potsdam, Germany.

E-mail addresses: karina.schollaen@gmail.com (K. Schollaen), ghelle@gfz-potsdam.de (G. Helle). 


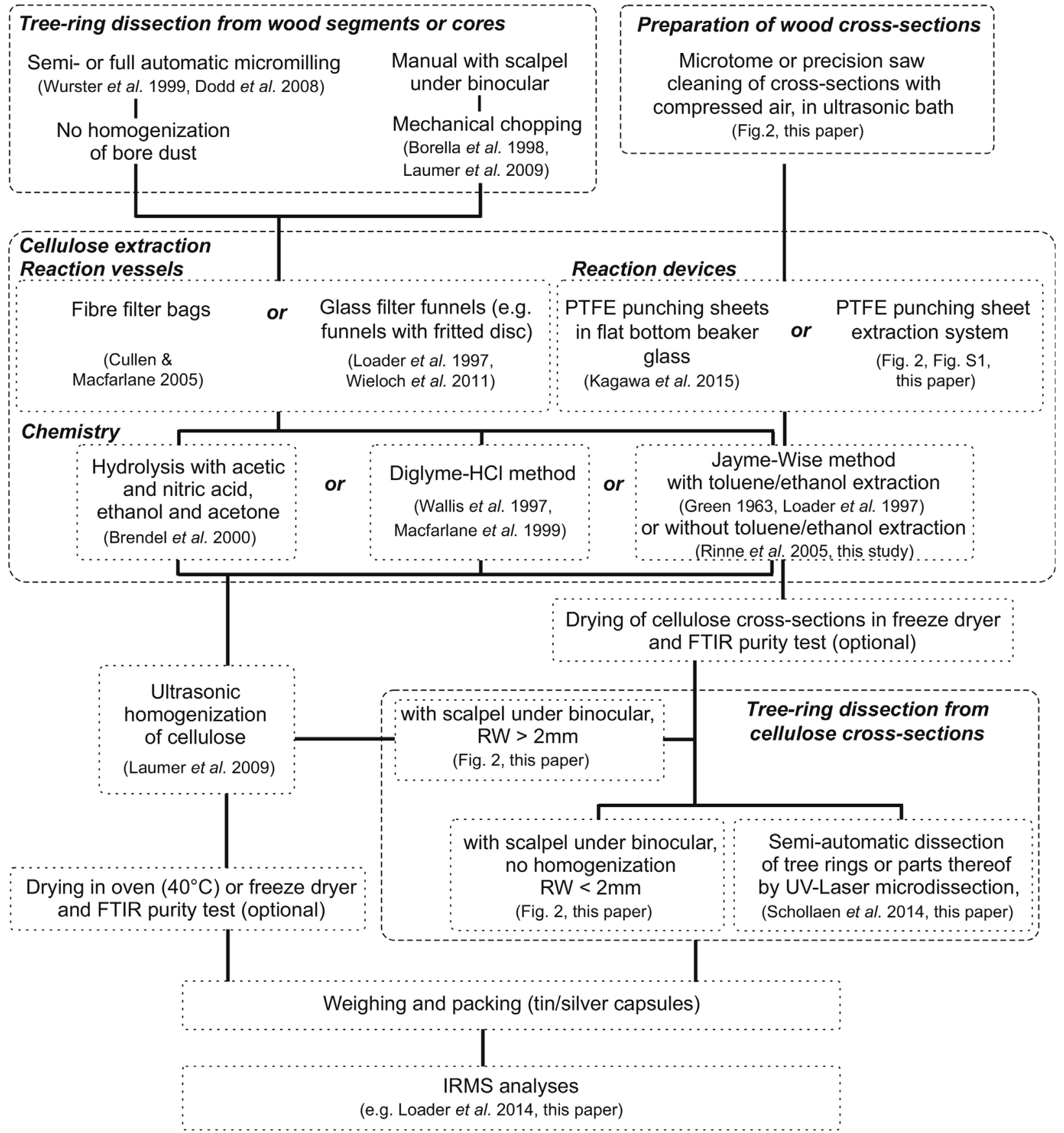

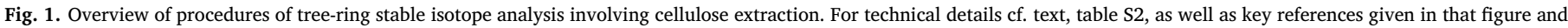
citations therein.

manual subdivision by scalpel, microtome or micromilling devices (e.g. Dodd et al., 2008; Wurster et al., 1999) prior to cellulose extraction. Despite novel technique developments, including the simultaneous chemical treatment of several hundred micro-samples (Wieloch et al., 2011) and individual homogenization (grinding or ultra-sonic treatment) (Laumer et al., 2009), chemical treatment of individual tree-ring samples was still required.

In order to reduce the cutting-grinding-chemical processing for each individual tree ring, Loader et al. (2002) made a first attempt to extract cellulose directly from standard increment cores $(5 \mathrm{~mm} \emptyset)$. More recently, Li et al. (2011) reported a technique to extract $\alpha$-cellulose directly from wood cross-sections using perforated U-channel PTFE casing to prevent cellulose spline from breaking apart. They conducted high-resolution intra-annual $\delta^{13} \mathrm{C}$ and $\delta^{18} \mathrm{O}$ analyses on a $3 \mathrm{~mm}$ wide rings from a $3.5-4.0 \mathrm{~mm}$ thick $\alpha$-cellulose cross-section, revealing no discrepancies from the usual method. A breakthrough in high sample throughput was achieved by Nakatsuka et al. (2011) with methodological improvements by Kagawa et al. (2015), where a container made of teflon (PTFE, polytetrafluoroethylene) punching sheet was designed to prevent disintegration of cellulose laths (see also Xu et al., 2011). The basic principle allows cellulose extraction from wood laths in a single batch, enabling the same chemical conditions for all samples, while significantly reducing time needed for cellulose preparation and retaining the wood cell structure.

Building upon on the idea of extracting cellulose from wood laths, we designed an improved semi-automated cellulose extraction system. The performance of this high-throughput cellulose extraction device was evaluated to provide precisely dissected, homogenous tree-ring 
cellulose samples for high-precision IRMS analyses. To validate the methodology, several coniferous and broadleaf tree species (different growth rates, tree-ring boundary shapes and cell structures) were tested. Furthermore, we compared Fourier transform infrared spectra (FTIR) and stable isotope ratios with results from the classical tree-ring preparation procedure according to Laumer et al. (2009) and Wieloch et al. (2011). We highlight differences between the cellulose extraction technique presented here and the approach by Kagawa et al. (2015). We embed the newly designed automated cellulose extraction system in a comprehensive guide of sample preparation: the Cross-Section Extraction and Dissection (CSED) guideline. The CSED guideline comprises pre-analyses considerations and specific measures for tree-ring dissection for high-precision isotope ratio mass spectrometry. In particular, potential effects of contaminants (e.g. pencil marks, chalk and maize starch) were tested on the original isotope composition $\left(\delta^{13} \mathrm{C}, \delta^{18} \mathrm{O}\right)$ of samples. Pencil and chalk are commonly used in dendrochronology and - ecology to highlight the contrast between different wood cell structures and improve the detection of narrow or indistinct annual growth boundaries during microscopic tree-ring measurements. In addition, many studies apply a mixture of maize starch, water and glycerol (so called non-Newtonian fluid) to the wood surface to penetrate the cell lumens and stabilize the cell walls during microsectioning (Schneider and Gärtner, 2013). However, original stable isotope ratios may be altered if these potential contaminants cannot be removed prior to analysis. This is becoming increasingly important as not only tree ecophysiological but also dendroclimatological studies are combining quantitative wood anatomical measures with stable isotope analysis for improved understanding of tree structure and related function (e.g. Szymczak et al., 2014). The guideline presented here addresses these recent developments.

\section{Preliminary consideration: wood or cellulose?}

Wood is a chemically complex material made of various components (cellulose, resins, lignins) with divergent isotopic signatures. Consequently, using wholewood for stable isotope analysis can cause signal distortion due to changing mass proportions of the different wood components. Thus, cellulose is often the preferred sample material which emphasizes the need for a fast and accurate extraction procedure.

Theoretically, carbohydrates from primary metabolism (i.e. sugars, starch or cellulose) have significantly different - normally heavier isotopic signatures than secondary metabolites (e.g. lignin or fatty acids). Accordingly, cellulose is always found enriched in ${ }^{13} \mathrm{C}$ over lignin or fatty acids by $2-4 \%$ according to a non-statistical distribution of 13C in cellulose precursers (Schmidt et al., 1998 and refs therein). Similarly, non-statistical 180 distributions originating from individual biosynthetic reactions lead to general differences between carbohydrates (cf. Schmidt e tal. 2001 for further details). Cellulose and hemicelluloses together form the largest part within wood (on average 65-75\%) (e.g. Kürschner and Popik, 1962; Pettersen, 1984), but they have a smaller absolute carbon content than lignin (almost 50\% lower). Therefore, the carbon signature of wholewood is predominantly a signature of the lignin component. The relative mass proportion between cellulose and lignins changes within the wood along the time-axis (pith to bark), affecting the interpretation of long isotope records. Moreover, extractives (fatty acids, waxes, alkaloids, proteins, phenolics, pectins, gums, resins, terpenes, starch, glycosides, saponins and essential oils) may represent an additional contribution of carbon, oxygen and hydrogen, which show a wide range of $\delta$-values as they are derived from the secondary plant metabolism (Schmidt et al., 1998; Schmidt et al., 2001). Extractives obtained from woody species growing in temperate climates constitute $4-10 \%$ of dry weight, but their portions may increase up to $20 \%$ in tropical trees (Pettersen, 1984). Nonetheless, their contribution to the overall $\delta^{13} \mathrm{C}$ value of wood may be negligible if these extractives make up only a small percentage of the wood and/or if the isotope values of these fractions are mainly in the ranges of cellulose and lignin. Extractives can frequently be related to specific extreme environmental conditions (e.g. fire or drought), which may induce resin production or be a defence mechanism against microbial and/or herbivore attack (e.g. Chapman, 1980; Guest and Brown, 1997; Schweingruber, 1996). These environmentally triggered changes in relative proportions of wood components may enhance or dampen the isotope signature predicted by models of isotope fractionation (e.g. Farquhar et al., 1982; Roden et al., 2000).

Several studies have tested whether wholewood or cellulose derived stable isotope chronologies better reflect environmental and climate variations, with contradictory results. Some of these studies suggest that cellulose extraction may not be necessary, since absolute differences between the stable carbon and oxygen isotope data of wood and cellulose were rather constant or revealed no difference in statistical relationship with environmental data (Barbour et al., 2001; Harlow et al., 2006; Verheyden et al., 2005). Hence, some studies have continued to use wholewood or resin-extracted wood in order to save time and money (e.g. Schollaen et al., 2013; Verheyden et al., 2004).

Conversely, it has also been reported that cellulose is a more stable proxy of past climate and therefore cellulose extraction is a necessary step in studies seeking to investigate climate signals (Battipaglia et al., 2008; Cullen and Grierson, 2006; Ferrio and Voltas, 2005; Szymczak et al., 2011). According to Loader et al. (2003), depending on the aim of the individual study both methods are applicable. Cellulose extraction may not be required when analysing long-term climate trends, while it may be more critical for information on extreme events such as droughts or high-rainfall years.

\section{Material and methods}

\subsection{Sample material}

Sample material from 10 tree species (Pinus sylvestris (subfossil), Quercus robur, Larix decidua, Tectona grandis, Picea abies, Cedrela lilloi, Juniperus seravschanica, Adansonia digitata, Pseudotsuga menziesii, Fagus sylvatica) growing at low to high elevation (timberline) sites in various climatic zones (boreal, temperate, tropical and semi-arid) were chosen. These represent different wood growth rates, tree-ring boundary shapes and a broad range of cell structure features. Additional information can be found in Table S1.

\subsection{Potential implications of contaminants}

In general, possible shifts of original isotope values from contaminants do not only rely on their isotopic deviation from the sample material, but also on their relative contribution to the sample mass. Potential effects can be determined by the following equation:

Impact $_{\mathrm{con}}[\% o]=\left(\frac{\left.\left(m E_{\text {sample }} \times \delta n E_{\text {sample }}\right)+m E_{\text {con }} \times \delta n E_{\text {con }}\right)}{m E_{\text {sample }}+m E_{\text {con }}}\right)-\delta n E_{\text {sample }}$

with

Impact $_{\text {con }}$ impact of contamination,

E element of interest (e.g. carbon or oxygen),

$m E_{\text {sample, }} m E_{\text {con }}$ respective relative mass fractions of the element, e.g. carbon or oxygen in sample or contaminant,

$\delta^{\mathrm{n}} E_{\text {sample }}$ original $\delta$ value of a sample, e.g. $\delta^{13} \mathrm{C}$ or $\delta^{18} \mathrm{O}$ value of the cellulose sample,

$\delta^{\mathrm{n}} E_{c o n} \delta$ value of a contaminant, e.g. $\delta^{13} \mathrm{C}$ or $\delta^{18} \mathrm{O}$ of pencil, chalk or starch

To test potential implications of contaminating substances, we repeatedly applied maize starch, pencil lead and chalk to different wood samples for analysis of teak (Tectona grandis) - a ring porous to semi-ring porous wood species of the tropics. Substances of clay 
minerals with graphite (maize starch flour, pencil lead) and those consisting of calcium sulphate (palm oil, chalk) were used. Similar to cellulose $\left(\left[\left(\mathrm{C}_{12} \mathrm{H}_{20} \mathrm{O}_{10}\right)_{[\mathrm{n}]}\right]\right)$, starch contains mass fractions of oxygen and carbon of about $49 \%$ and $44 \%$, respectively. The chalk mass fraction of oxygen contributes about $56 \%$ to the total mass. Wood structure analyses on modern Scots pine (Pinus sylvestris) revealed a variable ratio of cell wall to cell lumen (Liang et al., 2013a; Liang et al., 2013b; Pritzkow et al., 2014). In earlywood, it was found to be approximately 50:50, while latewood cell wall proportion can reach $80-90 \%$. Hence, we expected significant contaminations of the woody carbon and oxygen isotope ratios, particularly from the maize starch as well as chalk, and depending on the relative earlywood and latewood widths within the individual tree rings.

The surfaces of wood cross-sections were prepared with a core microtome of the Swiss Federal Institute for Forest, Snow and Landscape Research (Gärtner and Nievergelt, 2010) to ensure empty cell lumens (i.e. no remains of wood dust from sanding). The starch containing non-Newton fluid or chalk was then repeatedly rubbed into the cells of $2 \mathrm{~mm}$ thick wood cross-sections with a surface of $15 \mathrm{~cm} \mathrm{x} \mathrm{ca.}$ $0.5 \mathrm{~cm}$ in size (ca. $7.5 \mathrm{~cm}^{2}$ ). Possible effects of pencil lead were tested by comparing different areas within individual tree rings marked and unmarked with pencils. The potential mass fractions were determined from repeated weighing of the wood cross-sections before and after the treatment. Stable isotope ratios of oxygen and carbon were measured from the contaminants as described in the next section.

\subsection{Stable isotope analysis}

Measurements of stable oxygen isotope ratios were carried out by high temperature TC/EA pyrolysis (at $1400{ }^{\circ} \mathrm{C}$ ) with reverse Helium flow, coupled online via Conflo IV to an IRMS Delta V Advantage (Thermo Fisher Scientific, Bremen, Germany). Cellulose samples were packed in silver capsules $(4 \times 3.2 \mathrm{~mm})$, stored in dessicators and kept in a vacuum dryer (at $50{ }^{\circ} \mathrm{C}$ ) for several days (approx. 7 days) prior to IRMS analysis. The autosampler, a modified Carlo Erba Elemental Analyzer AS200 adapted to the TC/EA, is enclosed by a custom made housing that is continuously flushed with dry Argon gas during operation and contains a desiccant $\left(\mathrm{P}_{2} \mathrm{O}_{5}\right.$, phosphorus pentoxide) to ensure samples cannot take up humidity from laboratory air. Stable carbon isotopes (cellulose packed in tin capsules, $6 \times 4 \mathrm{~mm}$ ) were measured by combustion using an elemental analyser (Model NA 1500; Carlo Erba, Milan, Italy) coupled online via open split to an Isoprime IRMS (Isoprime Ltd, Cheadle Hulme, UK). The operating temperature of the combustion oven was set to $1060{ }^{\circ} \mathrm{C}$. The masses of the cellulose samples and reference materials for stable carbon and oxygen isotope analyses lied between 180 and $220 \mu \mathrm{g}$ and $130-160 \mu \mathrm{g}$, respectively. The analytical precision $\left(2 \sigma \pm 0.1 \%\right.$ for $\delta^{13} \mathrm{C}$ and $1 \sigma \pm 0.3 \%$ for $\delta^{18} \mathrm{O}$ ) was monitored constantly by measurements of internal and external reference material: $\delta^{18} \mathrm{O}$ values of used standard material were calibrated and normalized on IAEA 601 and IAEA 602 scale. According to Brand et al. (2009) reference values for IAEA 601 and IAEA 602 are $23.15 \% 0$ and $71.28 \%$, respectively. $\delta^{13} \mathrm{C}$ values of used standard material were calibrated and normalized on NBS 19 and LSVEC scale with the corresponding internationally distributed reference material IAEA CH-6, IAEA CH-3 and IAEA CH-7 scale, certificated value are $-10.449 \%$, $-24.724 \%$ and $-32.151 \%$, respectively. For all analyses, Helium 5.0 was used as carrier gas. The isotope ratios are given in the delta $(\delta)$ notation, relative to the standards VPDB (Vienna-PDB) for $\delta^{13} \mathrm{C}$ and VSMOW (Vienna-SMOW) for $\delta^{18} \mathrm{O}$ (Craig, 1957; Hut, 1987).

\subsection{Fourier Transform Infrared (FTIR) spectroscopy}

The chemical purity of the (holo-)cellulose obtained by the crosssection method as compared to the classical extraction method was evaluated by applying FTIR spectrometry to identify the functional groups for resin, lignin, $\alpha$-cellulose and hemicellulose. Furthermore, we compared the spectra of cellulose/wood obtained from reference material (Fluka cellulose; Lot. \& filling code 380099/1 20200) and untreated wholewood. The FTIR spectra were measured by direct absorbance using the potassium bromide $(\mathrm{KBr})$ pellet technique. $1 \mathrm{mg}$ of material was mixed with $450 \mathrm{mg}$ of $\mathrm{KBr}$-powder and pressed into thin pellets. The resultant pellets were vacuum dried at $50{ }^{\circ} \mathrm{C}$ for $24 \mathrm{~h}$ before placing them on a Vertex $80 \mathrm{v}$ FTIR-spectrometer (Bruker Optics, Germany). Each spectrum was measured at a spectral resolution of $2 \mathrm{~cm}^{-1}$ and 128 scans were conducted per sample.

\subsection{Cellulose extraction}

Cellulose extraction from wood can be achieved by different methods. The vast majority of studies and laboratories apply the Jayme-Wise method (Green, 1963; Loader et al., 1997) with $\mathrm{NaOH}$ and $\mathrm{NaClO}_{2}$ as key reagents. Hence, we also used this chemistry that has been validated in an international inter-laboratory comparison (e.g. Boettger et al., 2007) and recently found most suitable for mummified wood (Hook et al., 2015).

Independent from the cellulose extraction chemistry, classical cellulose extraction is performed on wood slithers (tangential slices of a few tenth of a millimeter in thickness taken from tree rings by microtome) or coarsely ground to finely milled wood particles (taken by scalpel or micromilling devices) (Fig. 1). Due to the various sizes of samples used for the cross-section extraction method, and thus an altered surface area reaction, resultant cellulose purity is an important factor to consider. Here, the chemical purity of cellulose was evaluated by FTIR and isotope $\left(\delta^{18} \mathrm{O}, \delta^{13} \mathrm{C}\right)$ ratios of cellulose produced by the cross-section extraction method and compared with those obtained from the 'Classical Method' according to Wieloch et al. (2011). This comparison was performed on two teak trees as well as different parts of the stems, inner heartwood and outer sapwood, representing separate time periods within the trees' lifes. The sapwood area is responsible for the water transport between root and crown of a tree and it largely consists of living parenchyma, responsible for storing reserves. The heartwood area usually is highly lignified and it no longer contains living wood cells. Hence, both wood sections generally differ considerably in their content of fatty acids, lignin and non-cellulosic polysaccharides. The strength of the linear relationships between the stable isotope tree-ring series were assessed by Pearson's correlation coefficients (r).

\subsection{Application of UV-laser microscope dissection}

Different ways exist to dissect tree rings or parts thereof (Fig. 1). In this study not only manual tree ring dissection using a scalpel was applied, but also UV-laser microscope dissection for intra-annual $\delta^{18} \mathrm{O}$ analyses from an African baobab to test the practical application of high precision UV-laser dissection on tree-ring cellulose cross-sections. The baobab sample was collected on the Eastern shore of Lake Kariba in the northern part of Zimbabwe in 2011. The UV-laser microdissection microscope of Leica LMD7000 (v6.7.1.3952, Leica Microsystems $\mathrm{GmbH}$ ) was used to dissect the cellulose cross-section, $0.8 \mathrm{~mm}$ thick (Fig. 5c) and was subdivided into 55 sections for high-resolution intraannual $\delta^{18} \mathrm{O}$ analyses. The sample masses of the sections ranged between $60 \mu \mathrm{g}$ to $130 \mu \mathrm{g}$ and the cutting area between 730 and $1800 \mu^{2}$. For details on UV-laser based microscopic dissection of tree rings see Schollaen et al. (2014).

\section{CSED guideline at a glance}

\subsection{Overview}

To obtain tree-ring stable isotope data from cellulose cross-sections, we follow a preparation scheme that requires 10 steps (Fig. 2). Fig. 1 puts our guideline of sample preparation in the framework of existing 

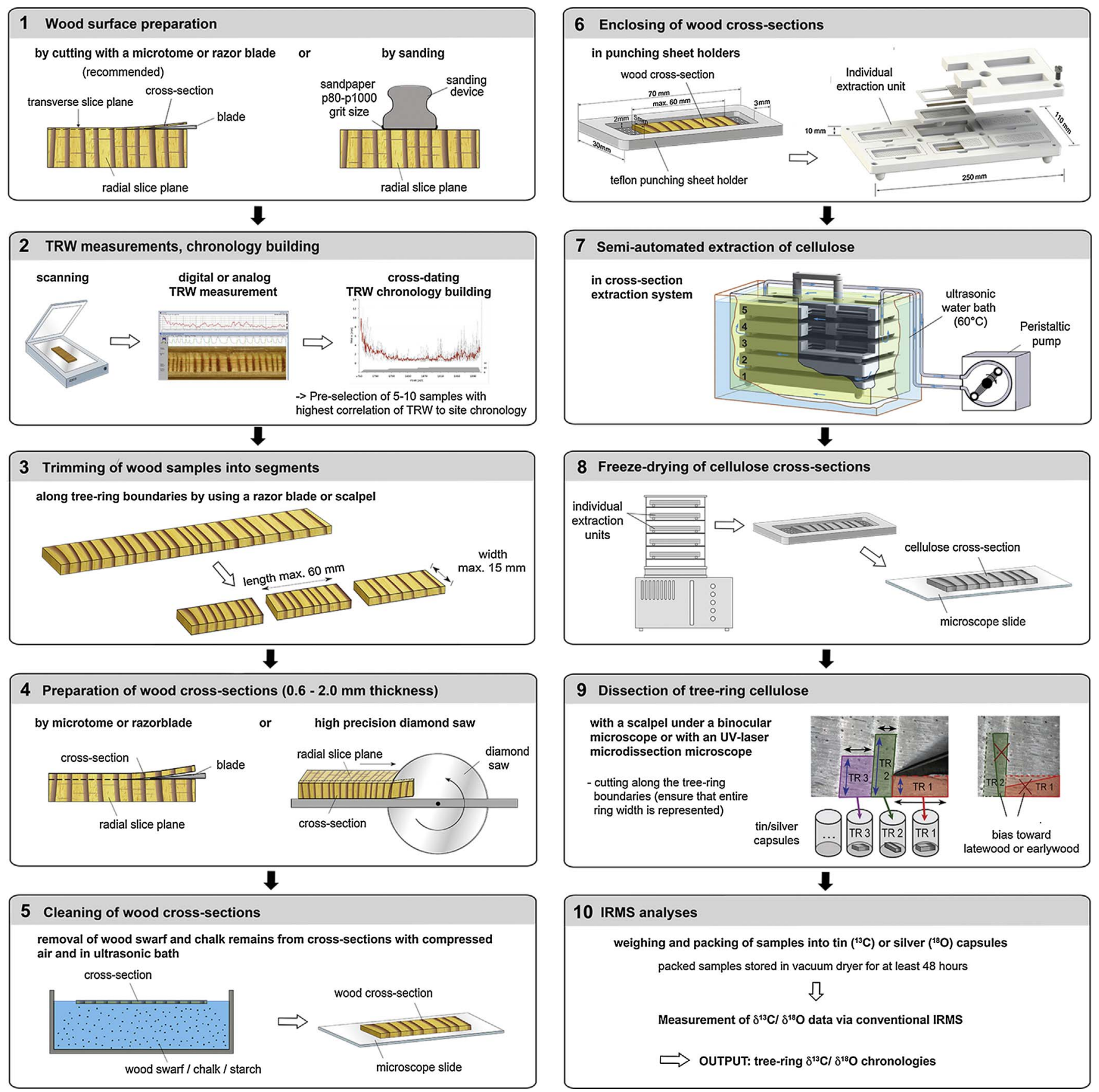

10 IRMS analyses

weighing and packing of samples into tin $\left({ }^{13} \mathrm{C}\right)$ or silver $\left({ }^{18} \mathrm{O}\right)$ capsules

packed samples stored in vacuum dryer for at least 48 hours

ת

Measurement of $\delta^{13} \mathrm{C} / \delta^{18} \mathrm{O}$ data via conventional IRMS

$\Rightarrow$ OUTPUT: tree-ring $\delta^{13} \mathrm{C} / \delta^{18} \mathrm{O}$ chronologies

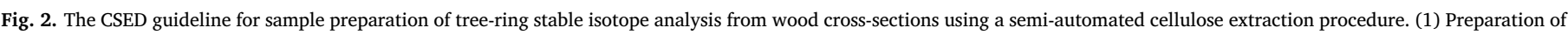

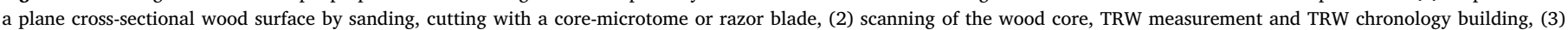

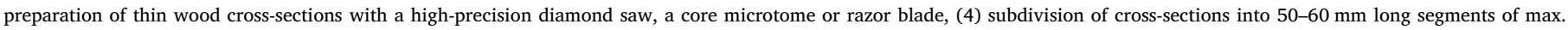

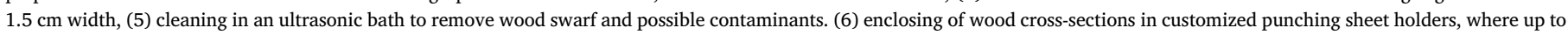

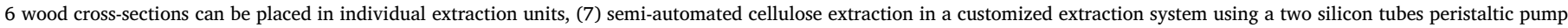

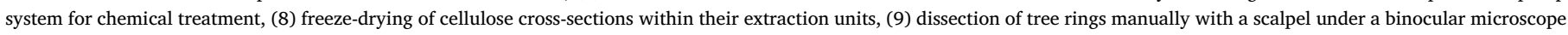

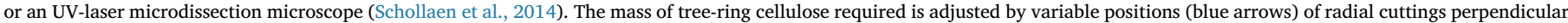

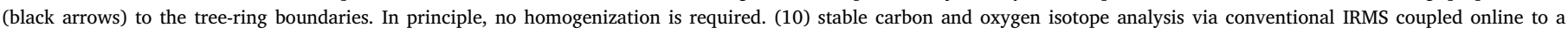

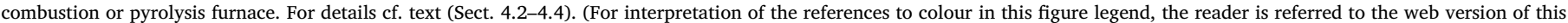
article.)

procedures and Fig. 2 focuses on the new aspects describing all steps at a glance: from wood sample preparation to the measurement of treering stable isotope data. The procedure provides specimens that are ready for IRMS analysis, but also allows other dendrochronological methods to be applied (e.g. quantitative wood anatomy), since large parts of the original samples (wood cores/segments) remain intact. The experimental design is explained in more detail in the following subsections.

\subsection{Preparation of wood cross-sections}

The wood surface is first prepared by a razor blade, microtome or sanding machine (Fig. 2, step 1). For better handling, we recommend to fix wood cores on a carrier material. 
The prepared wood segments are scanned and tree-ring widths (TRW) are measured (Fig. 2, step 2) following dendrochronological procedures described by Cook and Kairiukstis (1990). We recommend using digital systems for tree-ring width analysis (e.g. WinDendro ${ }^{\mathrm{TM}}$, Regent Instruments Inc., Canada) in combination with direct visual control of very narrow tree-ring sequences using a binocular. After cross-dating and building a TRW chronology, 5-10 trees with highest correlation to site chronology are selected for stable isotope measurements. We recommend the pre-selection of 5-10 trees as also recommended by Loader et al. (2013) to support sufficient coherence of signal for further dendroclimatic studies.

Wood cross-sections are separated along tree-ring boundaries into segments of 50-60 mm length and up to $15 \mathrm{~mm}$ width using a razor blade or scalpel (Fig. 2, step 3). Samples of such length are preferred, according to the size of the respective object holders, especially for treering dissection (binocular or for UV-laser-based microdissection), as well as for quantitative wood anatomy using confocal laser scanning microscopy (Liang et al., 2013a) or other techniques (e.g. von Arx et al., 2015).

Thereafter, wood cross-sections of varying thicknesses $(0.6 \mathrm{~mm}-2.0 \mathrm{~mm})$ are produced (Fig. 2, step 4) using a special highprecision, water cooled, diamond saw (IsoMet 5000 with a $15 \mathrm{HC}$ precision sectioning blade, ITW Test \& Measurement GmbH, Düsseldorf, Germany). The diamond saw was modified at the GFZ for handling samples of up to $30 \mathrm{~cm}$ in length. Accordingly step 3 and 4 could be done in reverse.

Alternatively and depending on the properties of sample material, a microtome (Gärtner and Nievergelt, 2010) or any other appropriate saw (e.g. a double bladed saw, Dendrocut from Walesch Electronics GmbH, Illnau-Effretikon, Switzerland) or even razor blades (e.g. Li et al., 2011) could be used to produce the cross-sections. It is important that the samples do not heat up during that process to prevent damage to the wood structure. Very soft woods with high water content (e.g. African baobabs, Adansonia digitata, A. kilima) should either be frozen with liquid nitrogen and kept in dry ice during preparation of cross-sections, if the samples are still fresh and moist, or be freeze-dried after soaked with purified water. Freeze-drying was found to cause a material shrinkage of less than $5 \%$. Both treatments provide sufficient durability for the cutting process to ensure accurate cross-sections.

Potential effects of contaminants (c.f. paragraphs $3.2 \& 5.1$ ) may be removed by using compressed air and an ultrasonic bath (Fig. 2, step 5). The cleaned and dried wood cross-sections were stored between well labeled microscopic slides $(26 \times 76 \mathrm{~mm}$, Thermo Fisher Scientific; Menzel GmbH, Braunschweig, Germany).

\subsection{Production of cellulose cross-sections (using a newly designed semi- automated cellulose extraction system)}

For the cellulose extraction, the cleaned wood cross-sections are enclosed in punching sheet holders made of teflon that are numbered for identification. Several sample holders accommodate wood crosssections of up to $2 \mathrm{~mm}$ thickness and maximum widths of $15 \mathrm{~mm}$ (e.g. from 5 or $10 \mathrm{~mm}$ increment cores), in combination with spacer slides (Fig. 2, step 6). The holders are then fixed in six rectangular wells and enclosed in a casing with a lower and upper mount. Both mounts are fitted together and fixed with screws. The six punching sheet holders placed in the casing build up an individual extraction unit (Fig. 2, step 6). Several of these individual extraction units (max. 5) can be placed on top of each other, resulting in a maximum of 6 increment cores of $30 \mathrm{~cm}$ in length that can be extracted at the same time (Fig. 2, step 7). The extraction device is placed into an appropriate container (e.g. glass), accommodating the relevant chemical solutions and completing the extraction system, which is then positioned in an ultrasonic water bath with a constant temperature of $60{ }^{\circ} \mathrm{C}$. Additional information and technical drawings regarding the extraction device can be found in Fig. S1 and Note S1.
After cellulose extraction, the extraction device or its individual extraction units with the thin-section cellulose samples are taken out of the (glass) container and stored in a freezer at $-20{ }^{\circ} \mathrm{C}$. We found out that bending or curling of particularly thin or fragile cross-sections can be avoided, if the individual teflon units along with the cellulose crosssection is lined with foil and filled with milli-Q water prior to freeze drying. Thereafter, the frozen cellulose cross-sections can be freezedried within their extraction units for two days before carefully taken out with forceps. Dry cellulose cross-sections are kept between two labeled microscope slides that are fixed with a clamp or adhesive tape (Fig. 2, step 8).

This study focuses on holocellulose, because isotopic differences between holo- and $\alpha$-cellulose were found to be relatively small (ca. $0.25-0.3 \%$ for $\delta^{13} \mathrm{C}$ and $\delta^{18} \mathrm{O}$, Boettger et al., 2007) and rather constant in time (Wieloch et al., 2011 and refs. therein). However, the additional step of $\alpha$-cellulose extraction with $17 \% \mathrm{NaOH}$ at room temperature can easily be performed as shown in earlier approaches by Nakatsuka et al. (2011).

\subsection{Tree-ring dissection from cellulose cross-sections}

Tree rings, or parts thereof (e.g. earlywood/latewood), can be dissected from cellulose cross-sections by manual dissection with a scalpel under a binocular microscope or by UV-laser microscopic dissection (Fig. 2, step 9). Tree-ring samples need to be cut along the tree-ring boundaries with great caution, ensuring that the entire ring width is represented by the isotope sample (Fig. 2, step 9). The exact sample masses required for IRMS analysis can be achieved by dissecting tree rings tangentially along their boundaries, ensuring that the entire ring width is represented. The proper size of the cutting area can be calculated if the thickness of the cellulose cross-section is known and the earlywood-to-latewood proportions do not vary significantly. To avoid bias of late- or earlywood proportion, care must be taken that the dissected specimen comprises the whole tree-ring width (black arrows in Fig. 2, step 9) and radial cuttings are performed perpendicular to the tree-ring boundaries (blue arrows in Fig. 2, step 9). This results in specimens of different sizes/volumes but similar mass and ensures that all samples have the appropriate weight and are homogenous representatives of the individual tree rings. The sample weight is controlled with a microbalance (e.g. AX26 DeltaRange; Mettler Toledo GmbH, Greifensee, Switzerland). Assuming that the relative proportions of earlywood and latewood width are kept, homogenization is not required and cellulose can be loaded directly into tin or silver capsules for carbon and oxygen isotope analysis, respectively. The ultrasonic homogenization is only required if tree-ring widths are so extensive that the sample weight of the dissected specimen would be too high for IRMS.

When ring widths are very narrow and/or growth ring boundaries are curved or asymmetric, the dissection with an UV-laser is advantageous (Schollaen et al., 2014). This has also been found in the subfossil pine samples, which often cannot be collected at breast height. Consequently, near-root samples frequently can contain tangentially curved ring boundaries which can be dissected more precisely with the high precision UV-laser cutting. Apart from UV-laser dissection, the use of UV-light can facilitate the visualization of tree-ring structures (see Fig. 4, juniper), due to heterogeneous density within each tree ring (e.g., latewood cellulose is more dense than earlywood cellulose), denser parts of a tree ring have a higher fluorescence.

For archiving purposes, the processed cellulose cross-sections are kept between two labeled microscope slides that are fixed with a clamp or adhesive tape and are stored for possible sample replication.

Tree-ring dissection, homogenization and immediate preparation for IRMS will be discussed in chapter 6.2.2. 
Table 1

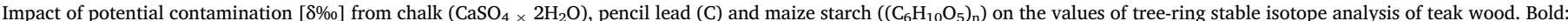

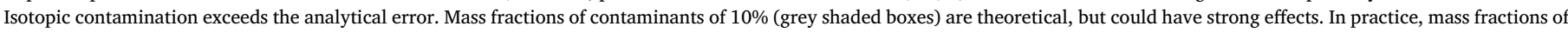

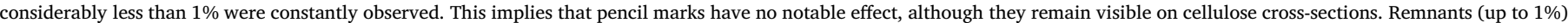

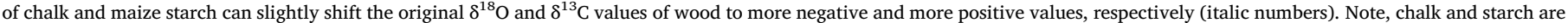
being removed during cellulose extraction (cf. text for more details).

\begin{tabular}{|c|c|c|c|c|c|c|c|c|c|c|}
\hline & & & \multicolumn{4}{|c|}{$\delta^{13} \mathrm{C}_{\text {wood }}$} & \multicolumn{4}{|c|}{$\delta^{18} \mathrm{O}_{\text {wood }}$} \\
\hline & & & $\min$ & $\max$ & $\min$ & $\max$ & $\min$ & $\max$ & $\min$ & $\max$ \\
\hline \multicolumn{3}{|c|}{ mass fraction of contaminant $[\%]$} & 1 & 1 & 10 & 10 & 1 & 1 & 10 & 10 \\
\hline \multicolumn{3}{|c|}{ original value $[\% 0]$} & -25.9 & -23.6 & -25.9 & -23.6 & 20.1 & 22.9 & 20.1 & 22.9 \\
\hline \multirow{2}{*}{ chalk } & \multirow{2}{*}{$\delta^{18} \mathrm{O}$} & 5 & & & & & -0.15 & -0.18 & -1.51 & -1.79 \\
\hline & & 8 & & & & & -0.12 & -0.15 & -1.21 & -1.49 \\
\hline \multirow{2}{*}{ pencil } & \multirow{2}{*}{$\delta^{13} \mathrm{C}$} & -28 & -0.02 & -0.04 & -0.21 & -0.44 & & & & \\
\hline & & -16 & 0.10 & 0.08 & 0.99 & 0.76 & & & & \\
\hline \multirow{4}{*}{$\begin{array}{l}\text { maize } \\
\text { starch }\end{array}$} & \multirow{2}{*}{$\delta^{13} \mathrm{C}$} & -14 & 0.12 & 0.10 & 1.19 & 0.96 & & & & \\
\hline & & -11 & 0.15 & 0.13 & 1.49 & 1.26 & & & & \\
\hline & \multirow{2}{*}{$\delta^{18} \mathrm{O}$} & 26 & & & & & 0.06 & 0.03 & 0.59 & 0.31 \\
\hline & & $36^{1}$ & & & & & 0.16 & 0.13 & 1.59 & 1.31 \\
\hline
\end{tabular}

${ }^{1}$ measured by Williams et al. (2005).

\subsection{IRMS analyses}

The final step in the CSED guideline is the measurement of stable isotope ratios via conventional IRMS (Fig. 2, step 10). For measurements of stable oxygen isotope ratios, packed samples are stored in a vacuum dryer for at least $48 \mathrm{~h}$ at $50{ }^{\circ} \mathrm{C}$, preferably in the corresponding metal carousels of the AS200 autosampler, or for several days at lower temperatures. For details of IRMS analyses see Section 3.3.

\section{Results}

\subsection{Possible influence of contaminants on stable isotope values}

The impact of potential contamination [ $\delta \% 0$ ] from pencil marks, chalk and maize starch on the tree-ring stable isotope values of wood is shown in Table 1. From repeated weighing, we determined a relative contribution of oxygen and carbon deriving from chalk and maize starch of less than $1 \%$ per tree ring. This indicates that the substances do not penetrate deeply into the wood cross-sections, despite partly high ratios of cell lumen vs. cell wall. The relative mass contributions of the pencil marks could not be measured as only some rings were marked and material from pencil lead was not rubbed into the cell lumens. However, woody tree species (exluding teak) show higher ratios of cell lumen vs. cell wall, allowing the calculation of contamination effects with mass fractions of $10 \%$; demonstrating possible isotopic shifts of more than $2 \%$ deviation from the original value (Table 1, bold numbers). Even remnants (up to 1\%) of chalk and maize starch can slightly shift the original $\delta^{18} \mathrm{O}$ and $\delta^{13} \mathrm{C}$ values of wood, exceeding the margins of analytical error (Table 1, italic numbers).

With respect to cellulose cross-sections, most of the contaminants were dispersed and removed by the ultra-sonic treatment (Fig. 2, step 5). Only pencil marks still remain visible on the cellulose cross-sections after the extraction, but can be bypassed while dissection of tree-rings. Most of the chalk and starch were completely dissolved during cellulose extraction at $60^{\circ} \mathrm{C}$. Even the poorly soluble gypsum remains from the chalk (solubility in water: $2 \mathrm{~g} / \mathrm{L}$ ) were dissolved.

\subsection{Purity of cellulose cross-sections}

The FTIR method is a well-known method to analyze the major wood components $\alpha$-cellulose, hemicellulose, lignin as well as extractives (e.g. Kagawa et al., 2015; Richard et al., 2014). We compared the spectra of (holo-)cellulose obtained by the cross-section and classical extraction method as well as reference material and untreated wholewood (Fig. 3). Main assignments of the IR-spectra are given in accordance with the literature (Anchukaitis et al., 2008; Harrington et al., 1964; Pandey and Pitman, 2003; Pandey and Theagarajan, 1997; Rinne et al., 2005). Many well-defined peaks exist (Fig. 3 red dotted lines) in the wood sample (green line), caused by functional groups of lignin: $1598 \mathrm{~cm}^{-1} / 1510 \mathrm{~cm}^{-1}$ for aromatic skeleton in lignin, $1460 \mathrm{~cm}^{-1} \mathrm{C}-\mathrm{H}$ from deformation and benzene vibration in lignin and $1270 \mathrm{~cm}^{-1} / 1227 \mathrm{~cm}^{-1}$ from $\mathrm{C}-\mathrm{O}$ stretching vibration in lignin. The absorption of hemicellulose components is around $1200 \mathrm{~cm}^{-1}$, $1375 \mathrm{~cm}^{-1}, 1732 \mathrm{~cm}^{-1}$ and for resin $1600 \mathrm{~cm}^{-1}$.

All of these lignin-related peaks were absent or significantly reduced in the spectra obtained by cross-section (blue lines) and classical (red lines) extraction method and no difference was visible between both extraction methods. The positions of bands are approximately the same as for the reference cellulose samples of Fluka- $\alpha$-cellulose (black line), suggesting successful removal of lignin.

The strong peak around $1650 \mathrm{~cm}^{-1}$, visible in all cellulose samples (except the wholewood and pine samples; classical method) is the only peak in the region between 1740 and $1510 \mathrm{~cm}^{-1}$ that still absorbs after the completion of the chemical treatments. Based on previous studies it seems to be caused solely by water linked to cellulose-OH (Harrington et al., 1984; Rinne et al., 2005 Rinne et al., 2005).

\subsection{Cellulose cross-sections from different tree species and UV-laser microscope application}

We found tree-ring structures to remain identifiable for a number of different coniferous and angiosperm tree species from various climate zones (boreal, temperate, tropical, semi-arid) and elevations (Fig. 4). Both the tree-ring boundaries and the basic tree-ring structures remained distinguishable. Characteristic features, such as tracheids 


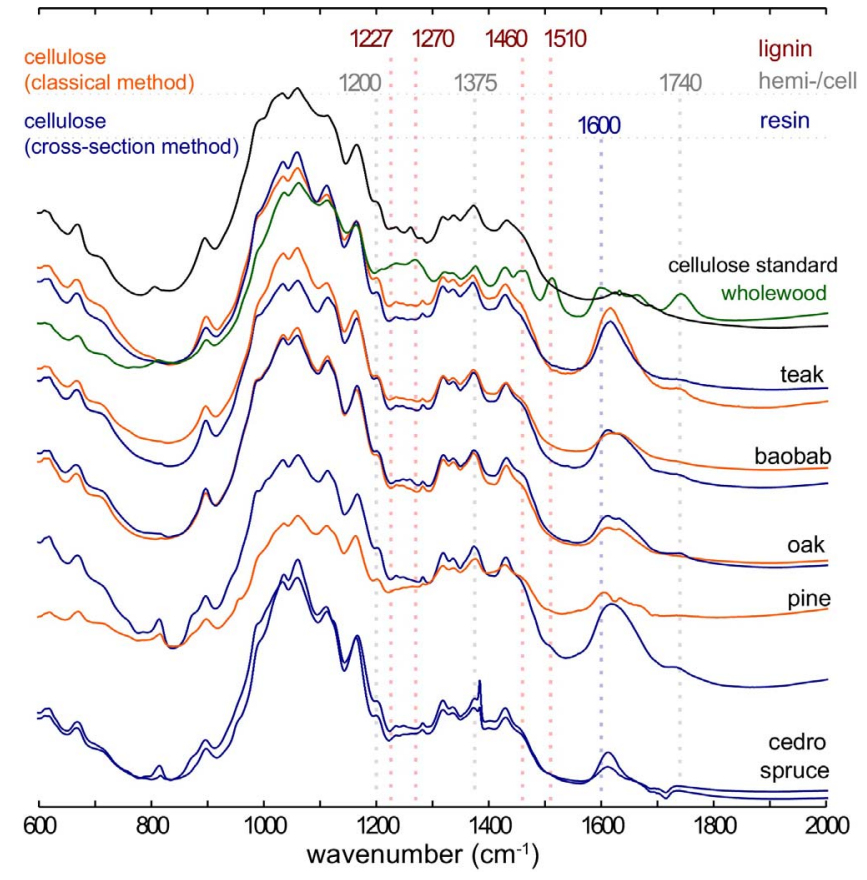

Fig. 3. FTIR (Fourier transform infrared) Spectra of wholewood (teak sample), cellulose standard (Fluka- $\alpha$-cellulose) and cellulose of different tree species produced with the classical versus cross-section method: teak (Tectona grandis), baobab (Adansonia digitata), oak (Quercus robur), pine (Pinus sylvestris), cedro (Cedrela lilloi), spruce (Picea abies). The vertical dotted lines show the wavenumbers related to lignin, hemicellulose and resin (Anchukaitis et al., 2008; Harrington et al., 1964; Pandey and Pitman, 2003; Pandey and Theagarajan, 1997; Rinne et al., 2005).

(see coniferous wood samples), vessels (see angiosperm wood samples), parenchyma bands (e.g. teak and baobab sample) or woody rays (e.g. oak sample) were equally visible in the wood and cellulose crosssections. Even rings which were very narrow or irregularly shaped, remained visible, as demonstrated here for larch and teak. Furthermore, the extraction method works for subfossil wood as was demonstrated for ten partly decomposed pine samples from the vicinity of Zurich, Switzerland (example of Pinus sylvestris, see Fig. 4, top left; Table S1 for site details).

Cellulose cross-sections extracted from a fragile African baobab sample allowed subsequent high resolution UV-laser dissection in radial direction (Fig. 5). Comparison with seasonal climate for Harare/ Zimbabwe revealed that the intra-annual $\delta^{18} \mathrm{O}$ pattern follows the annual cycle of $\delta^{18} \mathrm{O}$ in precipitation, as driven by quantity. High values in the beginning of the growing season (i.e. the rainy season from October to April) are followed by a decline to a seasonal minimum before $\delta^{18} \mathrm{O}$ marginally rises again at the end of the growing season.

Significantly high correlation coefficients $\left(\delta^{13} \mathrm{C}(\mathrm{n}=36)\right.$ : 0.98 , $\delta^{18} \mathrm{O}(\mathrm{n}=30)$ : 0.78$)$ and levels of common variance between the stable isotope datasets of both extraction methods were found (Fig. 6). The average difference between methods is $0.13 \%$ for carbon isotopes and $0.50 \%$ for oxygen isotopes. The extracted cellulose from the crosssection method resulted in similar isotope values as cellulose obtained by the classical extraction method.

\section{Discussion}

\subsection{Benefits of using cellulose instead of wood}

The question of wholewood or cellulose utilization to save cost and time at the expense of data quality has become superfluous when applying the cross-section cellulose extraction and tree-ring dissection procedure described here. We recommend the use of cellulose for stable isotope analysis, in particular, when emphasis is given to the impor-

\section{wood versus cellulose cross-sections of coniferous wood \\ angiosperm wood}
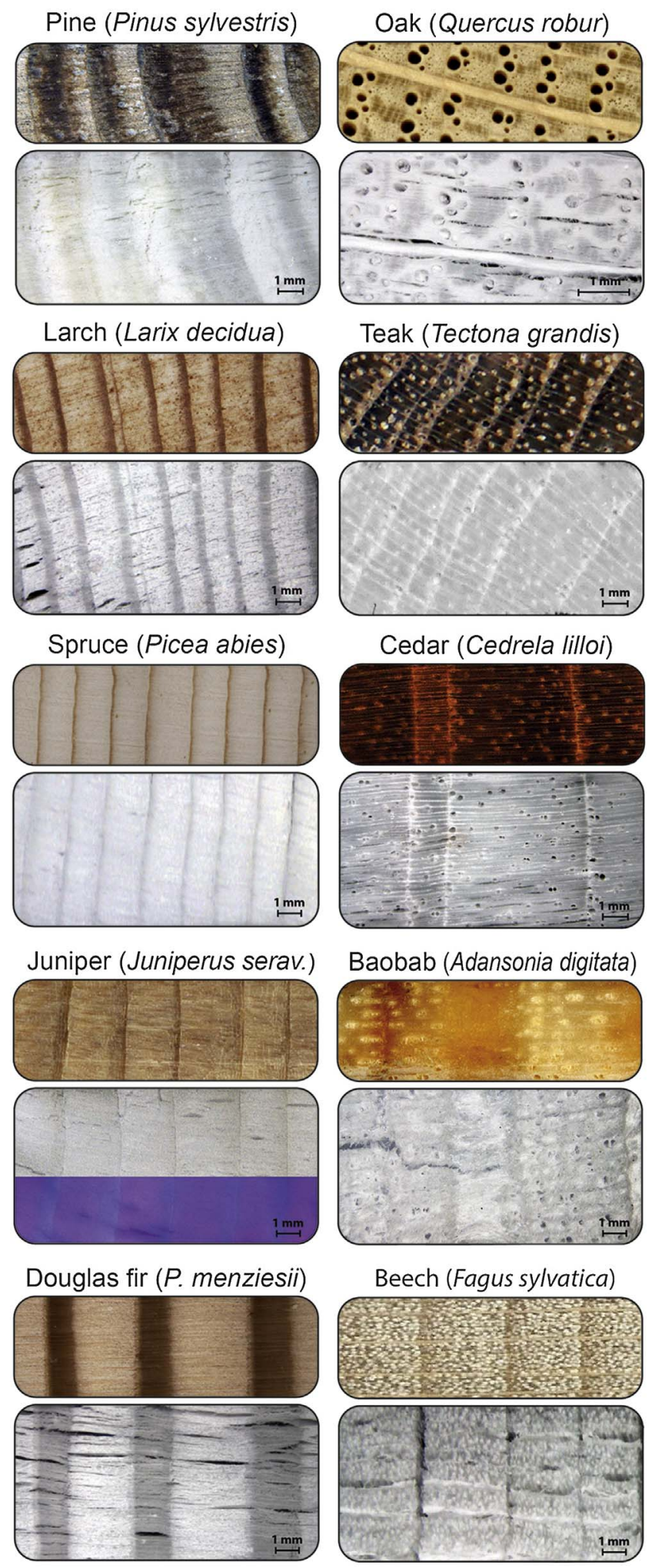

Fig. 4. Tree species tested for cellulose extraction and tree-ring dissection on crosssections. The upper pictures of each species show wood cross-sections while the lower pictures display the cellulose cross-sections obtained. Tree-ring structures remained clearly visible after the cellulose extraction process. The use of UV-light can help to detect tree-ring boundaries as shown for juniper. Table S1 for site details. 


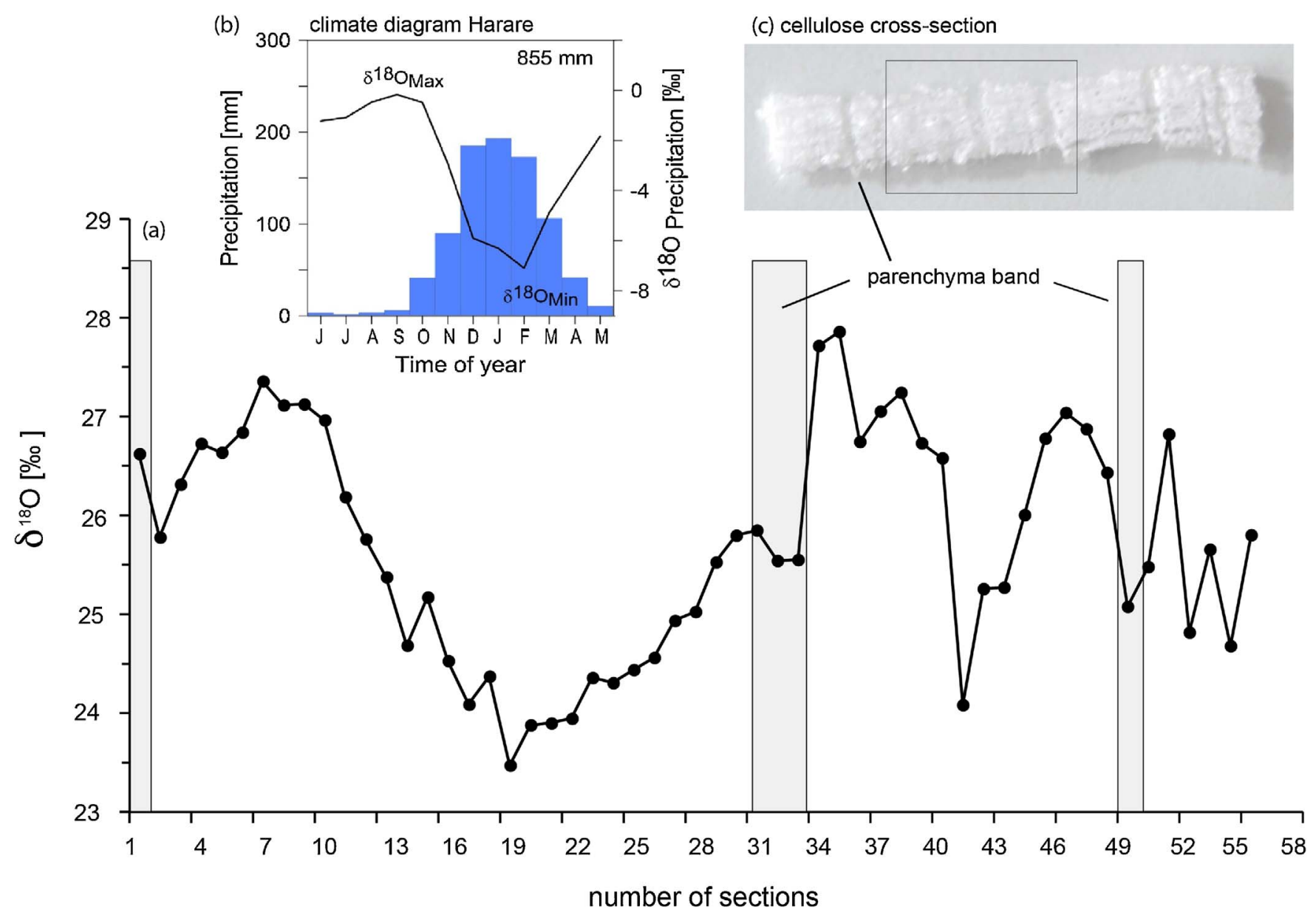

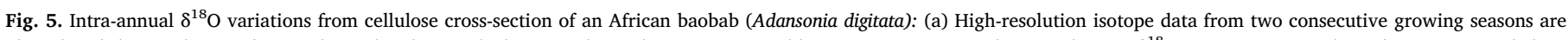

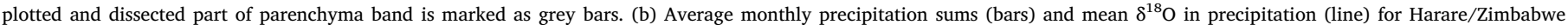

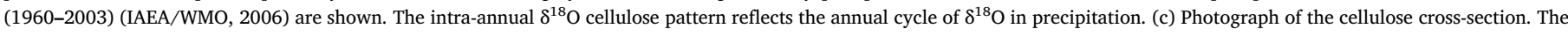
rectangle marks the analysed part of the cross-section.

tance of identical treatment of sample material ('IT principle', Brand et al., 2014; Carter and Fry, 2013; Werner and Brand, 2001), which should guide all isotope ratio determinations and evaluations.

Testing the potential influences of contaminating substances (maize starch, pencil marks, chalk) on the original stable isotope values of wood revealed no significant effects, as shown for chalk and pencil marks in a previous experiment (Schollaen and Helle, 2013). However, especially chalk and maize starch may slightly shift the original $\delta^{18} \mathrm{O}$ and $\delta^{13} \mathrm{C}$ values of wood samples. To prevent possible contamination of the original stable isotope ratios when using these auxiliary agents, we recommend the extraction of cellulose instead of using wholewood samples for dendro-isotopic studies. The application of mechanical (Fig. 2, step 5) and chemical treatments (Fig. 2, step 7) completely dissolves the contaminants, apart from the pencil marks. However, the contribution of pencil marks to the overall $\delta^{13} \mathrm{C}$ value of wood or cellulose was found to be negligible, as they do not make up a weighable percentage of the wood or cellulose and their $\delta^{13} \mathrm{C}$ values were generally found close to the ranges in cellulose and wood. Pencil marks help distinguishing wood anatomical features after cellulose extraction; particularly when studying cross-sections of diffuse porous tropical tree species without distinct parenchyma bands. To avoid a contamination of the sample material, pencil marks can easily be removed mechanically (by razor blade or scalpel).

\subsection{Evaluation of the CSED guideline}

The cross-section extraction and dissection procedure were tested on several tree species with different types of cell structures to evaluate the practical application of the method. In general, the cross-section extraction method worked well for both coniferous and angiosperm wood (Fig. 4). Subfossil (coniferous) wood can also be treated properly with this method, if it is not severely decomposed. The use of UV-light can facilitate the visualization of the tree-ring structures, as demonstrated for juniper.

\subsubsection{The cross-section cellulose extraction system}

The cellulose chemical purity tests obtained from the cross-section extraction method confirm the findings of previous studies (Kagawa et al., 2015; e.g. Li et al., 2011). We found no significant FTIR peaks of lignin or resins in any cellulose sample (Fig. 3). The cellulose extraction procedure was precise, as supported by FTIR spectra and the very highgrade synchronicity compared to the classical method (Fig. 6). Studies by Li et al. (2011) and Kagawa et al. (2015) also reported no significant differences between the classical and the cross-section method $\left(\mathrm{R}^{2}=0.977\right)$, with an average difference between tree-ring isotope ratios of both methods of $0.06-0.12 \%$ and $0.001 \%$, respectively.

The cross-section extraction method has several benefits compared to the classical extraction method: (1) the chemical treatment is consistent for all samples, (2) the renewal of $\mathrm{NaOH}-$ or $\mathrm{NaClO}_{2}$ solutions as well as the washing/neutralizing is easy, fast and works semi-automatic by using a peristaltic pump system, (3) the enrichment of chemical concentrations due to the evaporation of water over long extraction intervals is negligible compared to the usage of filter funnels for the cellulose extraction (Wieloch et al., 2011), (4) the procedure 

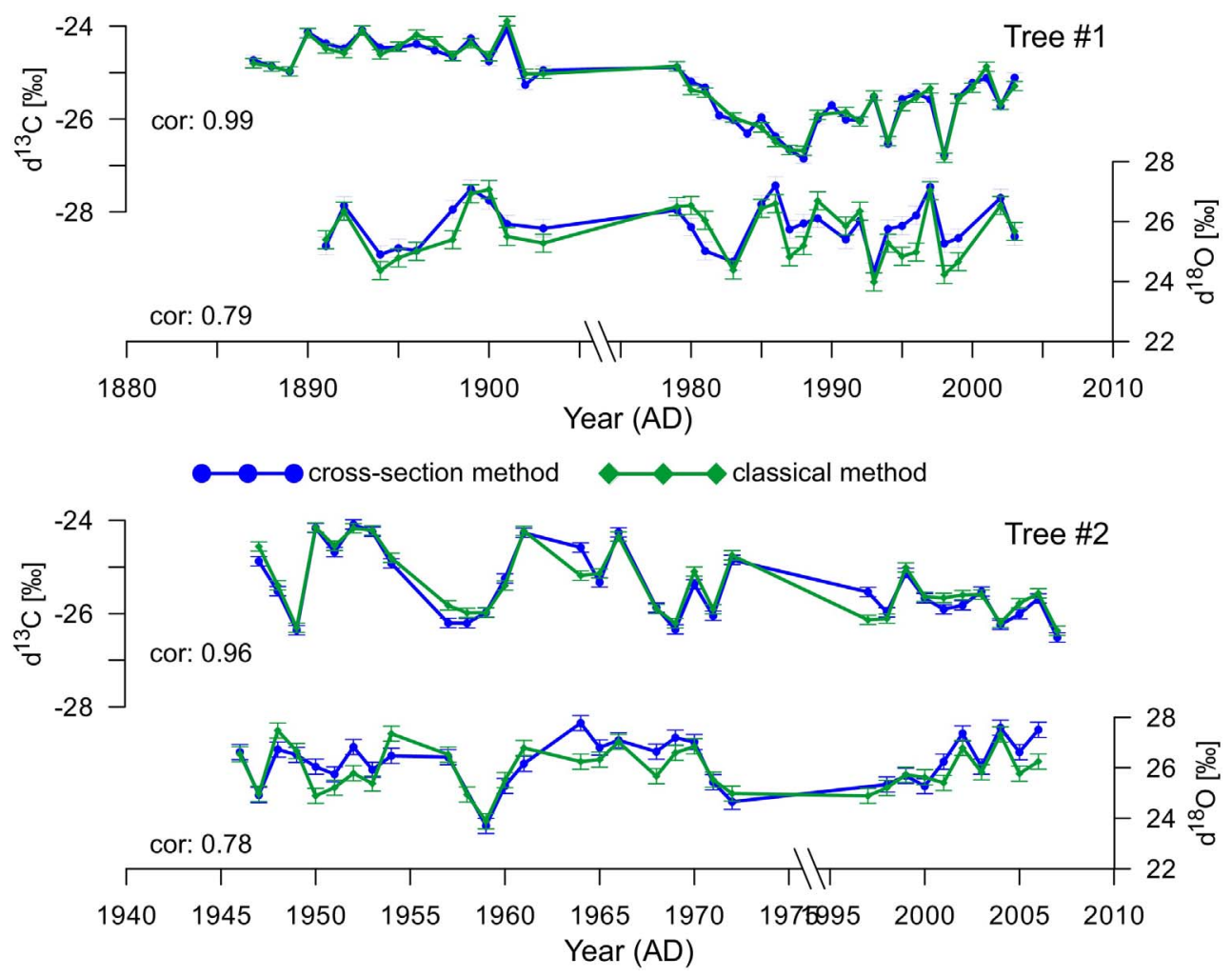

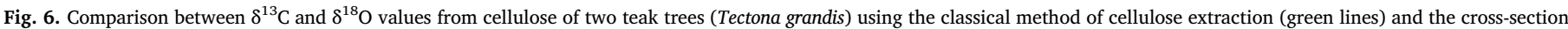

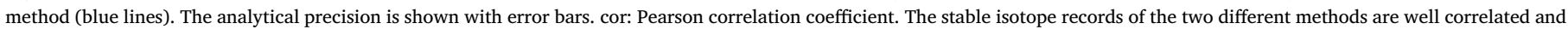

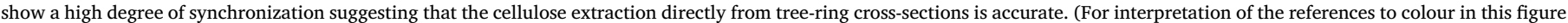
legend, the reader is referred to the web version of this article.)

saves time and causes minimal strain to particularly fragile thin sections from species with very low wood density, (5) tree-ring boundaries and cell structures remain visible (earlywood and latewood can easily be distinguished under a binocular with transmitted light), (6) the flexible use of custom designed teflon sheets within teflon casings allows cellulose extraction from wood cross-sections of variable sizes and thicknesses, (7) the use of cross-sections permits the simultaneous extraction of wood from numerous tree-ring samples, (8) cross-sections of up to $180 \mathrm{~cm}$ in length (corresponding to 6 wood cores of $30 \mathrm{~cm}$ length) can be extracted in one step, and finally (9) less space is needed in the laboratory for the extraction apparatus compared to the classical extraction method, i.e. only a small part of a fume hood is required for processing up to six wood increment cores.

The basic principle of this cellulose extraction method is similar to the method described by Li et al. (2011) and Kagawa et al. (2015). The dissimilarities and improvements to the published methods are: (1) the cross-section cellulose extraction system described here facilitates the horizontal position of cross-sections and ensures, together with the use of a peristaltic pump, a consistent chemical treatment of all samples, (2) due to the use of a peristaltic pump system the renewal of solutions works semi-automatically, (3) no time consuming sewing of punching sheets with potentially contaminating cotton threads (Kagawa et al., 2015) is needed to enclose the wood samples properly, and (4) it is possible to extract the cellulose of wood samples with a thickness of up to $3.5 \mathrm{~mm}$. However, much thinner cross-sections of trees with even fragile wood cell structure, like baobabs, are left intact after extraction. Caution needs to be exercised when ancient or subfossil wood samples with deteriorated cell structures are processed. Although our tests revealed that extraction from ancient, late-glacial pine wood is possible (c.f. Fig. 4, top left), problems can arise for sapwood parts of decayed wood. These outer portions exhibited discoloration and reduced wood stability, the former likely caused by residual resin or an alteration in wood content via preferential lignin degradation, a fact, which also indicates that cellulose is the better choice (over whole-wood) for stable isotope analysis. When sapwood appears unstable after preparing the cross-sections, it is advised to use the classical approach with tree ring dissection followed by cellulose extraction in filter bags or filter funnels.

For convenient handling we recommend the use of wood samples with a length no longer than $60 \mathrm{~mm}$, a width between 3-4 mm (up to $15 \mathrm{~mm}$ ) and a thickness from 0.6 to $2.0 \mathrm{~mm}$. Caution and further tests should be conducted if the cross-sections are outside the suggested range of thickness. Depending on the wood structure and state of preservation, cellulose cross-sections thinner than $0.6 \mathrm{~mm}$ usually are very fragile and subsequently difficult to handle. Cross-sections thicker than $2 \mathrm{~mm}$ are prone to breakage by overcrowding and may need a longer extraction with purity to be tested by FTIR. Furthermore, shrinkage during cellulose extraction or drying may cause distortions in vertical direction (parallel to wood fibres or vessels) or curling that may prevent precise and unambiguous dissection of defined tree rings. However, such effects are minimized due to the horizontal position of the wood cross-section in the extraction device introduced here. Processed cellulose cross-sections can be archived after cutting out the sample for IRMS analysis by inserting them between two labeled glass slides wrapped in clingfilm.

\subsubsection{Providing homogenous samples from cellulose cross-sections for} IRMS

Laumer et al. (2009) tested different homogenization approaches, including grinding the wood sample before extraction, homogenization of cellulose by freeze milling or ultrasonic treatment and concluding that all methods are applicable for stable isotope analysis. But, the substantial sample loss (about $28 \%$ on average, Laumer et al., 2009) and time intensive cleaning procedure by grinding or freeze milling makes these approaches unsuitable. Further, Isaac-Renton et al. (2016) tested possible contamination risk of stable isotope samples during 
milling and concluded that a ball mill can be used to homogenize samples within test tubes prior to oxygen isotope analysis, but not prior to carbon isotope analysis.

In comparison, the loss of sample material from ultrasonic homogenization of water-dispersed cellulose is negligible (less than $1 \%$, Laumer et al., 2009). However, oxygen isotopic exchange between sample and water due to increased temperatures from extensively long ultrasonic treatments is a known but frequently underestimated risk. Ultrasonic cavitation releases an extremely high energy per unit of volume, which greatly surpasses the break tension of the cellulose fibres. The mean bond dissociation enthalpy, namely $\mathrm{EH}_{\mathrm{m}}(\mathrm{HO}-\mathrm{H})$ for water is $492 \mathrm{~kJ} \mathrm{~mol}^{-1}$ and the single bond enthalpy $\mathrm{EH}_{\mathrm{m}}(\mathrm{O}-\mathrm{H})$ is $463 \mathrm{~kJ} \mathrm{~mol}^{-1}$ (Kaye and Laby, 1973). These values may not be reached during the ultrasonic treatment, but activation could be induced such that an exchange of isotopes could be facilitated by higher temperatures, potentially depleting $\delta^{18} \mathrm{O}$ values relative to the original cellulose samples. This may occur since $\delta^{18} \mathrm{O}$ values of cellulose from wood are in the range of 25-35\% and oxygen isotopes from de-ionized water normally show values around -5 to $-10 \%$ (Laumer et al., 2009). One may use larger amounts of sample material ( $>1 \mathrm{mg}$ ) in order to reduce inhomogeneity effects. However, many tree-ring records derived from long-lived trees at timberline sites rarely provide enough material because of their narrow and frequently wedging rings. This complicates the strategy of using larger amounts of sample material.

The sample mass desired for IRMS analysis can be obtained without extra homogenization by dissecting the tree rings precisely along the tree-ring boundaries (tangential direction), but with variable widths of cuttings in radial direction. This results in consistent specimens of rather similar weight despite variable ring widths. The specimens comprise the whole tree-ring width but vary in size, i.e. in tangential length parallel to the tree-ring boundaries (Fig. 2, step 9). In doing so, the cross-section dissection method may make (ultrasonic) homogenization obsolete (except for tree-ring widths $>$ approx. $10 \mathrm{~mm}$ ). Provided that the IRMS holds a good linearity and the person who is performing the tree-ring cellulose dissection is well experienced, weighing may no longer be necessary for each individual sample when following this procedure. The method takes advantage of modern online IRMS systems that are capable of analysing very small samples. The suggested way of separating tree rings from cellulose cross-sections which might be as thin as $0.6 \mathrm{~mm}$, results in very small amounts of samples, which are still representative for an entire tree ring. A disadvantage may be that sample replication requires greater effort and skills as additional samples cannot simply be taken from homogenized cellulose stored in a vial. Sample replication instead requires new dissection of tree rings manually with a scalpel under a binocular microscope or an UV-laser microdissection microscope.

In general, cellulose cross-sections are more difficult to handle and more prone to breakage than wholewood cross-sections, thus gentle handling during the extraction process and especially during manual tree-ring dissection is required. The scans of the wood segments support the following identification of tree-rings on the cellulose thin sections. However, cutting out small nooks at specific positions of the wood cross-section might be helpful as a marker for tree-ring boundaries.

\subsubsection{Tree-ring dissection with UV-laser microscope}

UV-laser-based microscopic dissection of cellulose thin sections is a great tool to achieve highly resolved and very precise intra-annual treering stable isotope measurements. Nevertheless, it can be challenging when working with very soft and light wood like baobab. In order to accumulate enough sample material for stable isotope measurements, either the radial cutting width or the thickness of the thin section needs to be adjusted accordingly. A wider sample, in terms of radial width, reduces the possible data points per tree ring, whereas a thicker crosssection increases the time required to cut the sample. The laser beam generally needs to be adjusted for different sample depths when cutting cellulose cross-sections, with each depth demanding one or more additional cutting processes through adjustments of the laser focus. Following the law of gravity, the disentangled sample will slowly move downwards, while the fibres of the sample and the surrounding material tend to interlock with each other. The cut sample can then be pushed with greatest caution with a suitable tool (e.g. forceps with fine tips or a dental explorer tool) or tackled repeatedly with the UVlaser. We counted up to ten cutting processes to successfully separate a $0.8 \mathrm{~mm}$ thick baobab cellulose sample from the cross-section. UV-laser microscope dissection is much more precise than conventional tree-ring separation using a scalpel, however, it is more time consuming. For details on UV-laser based microscopic dissection of tree rings see Schollaen et al. (2014).

The seasonal tree-ring $\delta^{18} \mathrm{O}$ pattern in the Zimbabwean baobab reflecting the annual cycle of $\delta^{18} \mathrm{O}$ in precipitation and corresponding seasonal changes in the amount of precipitation is well in line with former studies that showed significant correlations between tree-ring stable isotopes from baobab cellulose, extracted with classical methods, and rainfall data (Robertson et al., 2006; Slotta et al., 2017; Slotta et al., 2014; Woodborne et al., 2015). However, to our knowledge, this is the first time that high-resolution intra-annual $\delta^{18} \mathrm{O}$ cellulose values in baobab have been performed. Our results further demonstrate the African baobabs' potential for being a reliable palaeoclimatic proxy archive.

\section{Conclusions}

Based on an overview of existing procedures of tree-ring stable isotope analysis involving cellulose extraction, we present a detailed guideline for a semi-automated method of cellulose extraction from wood cross-sections and subsequent dissection of tree-rings or parts thereof (CSED guideline). The procedure was applied to different tree species with a broad range of various cell structures, wood growth rates as well as potentially different amounts of lignin and resin.

The CSED guideline describes the dissection of very narrow tree rings and offers potential for applying UV-laser-based microscopic dissection for highly resolved and very precise intra-annual tree-ring stable isotope analysis. Due to the use of cross-sections, multidisciplinary analyses on the same wood samples (tree-ring width, stable isotope, quantitative wood anatomy, wood density) are possible, since the stable isotope analysis no longer consumes entire wood cores. Furthermore, the question of whether or not cellulose extraction is required for stable isotope analysis on tree-ring chronologies has become superfluous, as cellulose extraction and sample homogenization are no longer a time limiting step.

The proposed CSED guideline optimizes stable isotope analysis due to its (1) rapid, inexpensive and user friendly cellulose extraction, and (2) precise tree-ring dissection at annual to high-resolution scale utilizing manual devices or UV-laser microdissection microscopes. The procedure may allow the analysis of individual tree-ring samples, where otherwise pooling (e.g. Dorado Liñán et al., 2011; Szymczak et al., 2012) would be required due to time and cost constraints.

Our guideline allows higher sample throughput than classical methods, with the simultaneous cellulose extraction of large quantities of wood ( $180 \mathrm{~cm}$ cross-sections: equivalent to 6 increment cores of $30 \mathrm{~cm}$ length) in a single step. The efficiency of solution exchange has been improved and sample homogenization made nonessential, but need more gentle handling. The overall procedure saves time, however, the possible saving is difficult to quantify. Preparing and extracting 1.800 individual tree rings from wood cores of $180 \mathrm{~cm}$ in length (with average ring widths of $1 \mathrm{~mm}$ ) may take two to three months or more when following the classical way. This time can virtually be halved.

A special focus of this study was put on tropical tree species, for which the application of stable isotope analysis to dendroclimatology is increasingly used. Stable isotope records from tropical woody plant species (e.g. Brienen et al., 2012; Baker et al., 2015; Ben et al., 2017; Schollaen et al., 2013; Schollaen et al., 2015) can improve the knowl- 
edge of tropical climate in the past and plant response to global change. The various tree samples presented here demonstrate that the CSED guideline can be applied in such cases, where alternative methods are often the only choice for successful tree-ring research (Heinrich and Allen, 2013). This opens new possibilities for studies on (sub-)tropical species with more complicated and particularly more fragile wood anatomical structures; e.g. the African baobabs (Adansonia spp.), a wide-spread and long-living species with high potential for providing stable isotope records of millennial length for climate reconstructions (Robertson et al., 2006; Slotta et al., 2014; Woodborne et al., 2015; Slotta et al., 2017).

\section{Acknowledgements}

We thank Akira Kagawa for his helpful comments during establishment of the cellulose extraction method on wood laths at the GFZ, Potsdam. We are grateful to Carmen Bürger and David Göhring for support in the laboratory, and to Jessica Baker, Kirstin Jansen, Hagen Pieper, and Bastian Ullrich for successfully testing the introduced method and providing sample images. We thank Michael Vogt for the technical design and construction of the extraction device, Andreas Hendrich for help with the layout of figures, and Monika Koch-Müller and Hans-Peter Nabein who enabled the FTIR spectrometry and gave valuable help with data interpretation. This study was funded by the Joint DFG/FAPESP Research Grant Proposal (HE3089/5-1), the DFGproposals (HE 3089/10-1 \& 11-1) and the CADY (BMBF, 03G0813H) project. This study is a contribution to the Virtual Institute of Integrated Climate and Landscape Evolution Analysis - ICLEA - of the Helmholtz Association, grant number VH-VI-415. This study thankfully used infrastructure of the TERENO Observatory NE.

\section{Appendix A. Supplementary data}

Supplementary data associated with this article can be found, in the online version, at http://dx.doi.org/10.1016/j.dendro.2017.05.002.

\section{References}

Anchukaitis, K.J., Evans, M.N., Lange, T., Smith, D.R., Leavitt, S.W., Schrag, D.P., 2008. Consequences of a rapid cellulose extraction technique for oxygen isotope and radiocarbon analyses. Anal. Chem. 80, 2035-2041.

Baker, J.C., Hunt, S.F., Clerici, S.J., Newton, R.J., Bottrell, S.H., Leng, M.J., Heaton, T.H., Helle, G., Argollo, J., Gloor, M., Brienen, R.J., 2015. Oxygen isotopes in tree rings show good coherence between species and sites in Bolivia. Glob. Planet. Change 133, 298-308.

Barbour, M.M., Andrews, T.J., Farquhar, G.D., 2001. Correlations between oxygen isotope ratios of wood constituents of Quercus and Pinus samples from around the world. Aust. J. Plant Physiol. 28, 335-348.

Battipaglia, G., Jäggi, M., Saurer, M., Siegwolf, R.T.W., Cotrufo, M.F., 2008. Climatic sensitivity of $\left({ }^{18} \mathrm{O}\right.$ in the wood and cellulose of tree rings: results from a mixed stand of Acer pseudoplatanus L. and Fagus sylvatica L. Palaeogeogr. Palaeoclimatol. Palaeoecol. 261, 193-202.

Ben, T., Hart, P.J., Helle, G., 2017. Towards establishing a new environmental archive - Annual growth periodicity, stable carbon isotope variability and reconstruction potential of 'Akoko (Euphorbia olowaluana), a native Hawaiian tree with C4 photosynthetic pathway. Erdkunde 71 (1), 77-92.

Boettger, T., Haupt, M., Knöller, K., Weise, S.M., Waterhouse, J.S., Rinne, K.T., Loader, N.J., Sonninen, E., Jungner, H., Masson-Delmotte, V., Stievenard, M., Guillemin, M.T., Pierre, M., Pazdur, A., Leuenberger, M., Filot, M., Saurer, M., Reynolds, C.E., Helle, G., Schleser, G.H., 2007. Wood cellulose preparation methods and mass spectrometric analyses of (13C, (18O, and nonexchangeable (2H values in cellulose, sugar, and starch: an interlaboratory comparison. Anal. Chem. 79, 4603-4612.

Brand, W.A., Coplen, T.B., Aerts-Bijma, A.T., Böhlke, J.K., Gehre, M., Geilmann, H., Gröning, M., Jansen, H.G., Meijer, H.A.J., Mroczkowski, S.J., Qi, H., Soergel, K., Stuart-Williams, H., Weise, S.M., Werner, R.A., 2009. Comprehensive interlaboratory calibration of reference materials for $\left({ }^{18} \mathrm{O}\right.$ versus VSMOW using various on-line high-temperature conversion techniques. Rapid Commun. Mass Spectrom. 23, 999-1019.

Brand, W.A., Coplen, T.B., Vogl, J., Rosner, M., Prohaska, T., 2014. Assessment of international reference materials for isotope-ratio analysis (IUPAC Technical Report). Pure Appl. Chem. 86, 425-467.

Brendel, O., Iannetta, P.P.M., Stewart, D., 2000. A rapid and simple method to isolate pure alpha-cellulose. Phytochem. Anal. 11, 7-11.

Brienen, R.J.W., Helle, G., Pons, T.L., Guyot, J.L., Gloor, M., 2012. Oxygen isotopes in tree rings are a good proxy for Amazon precipitation and El Niño-Southern Oscillation variability. Proc. Natl. Acad. Sci. 109, 16957-16962.

Carter, J.F., Fry, B., 2013. Ensuring the reliability of stable isotope ratio data-beyond the principle of identical treatment. Anal. Bioanal. Chem. 405, 2799-2814.

Chapman, R., 1980. Herbivores: Their Interaction with Secondary Plant Metabolites. In: Rosenthal, Gerald A., Hanzen, Daniel H. (Eds.), Academic Press Inc., New York, London, Sydney, Toronto and San Francisco xiii + 718 pages) $£ 34.60$, ISBN 012 597180 X. Elsevier Current Trends, 1980.

Cook, E., Kairiukstis, L.A., 1990. Methods of Dendrochronology Applications in the Environmental Sciences. Kluwer Dordrecht.

Craig, H., 1957. Isotopic standards for carbon and oxygen and correction factors for massspectrometric analysis of carbon dioxide. Geochimica et Cosmochimica Acta 12, $133-149$.

Cullen, L.E., Grierson, P.F., 2006. Is cellulose extraction necessary for developing stable carbon and oxygen isotopes chronologies from Callitris glaucophylla? Palaeogeogr. Palaeoclimatol. Palaeoecol. 236, 206-216.

Cullen, L.E., MacFarlane, C., 2005. Comparison of cellulose extraction methods for analysis of stable isotope ratios of carbon and oxygen in plant material. Tree Physiol. 25, 563-569.

Dodd, J.P., Patterson, W.P., Holmden, C., Brasseur, J.M., 2008. Robotic micromilling of tree-rings: a new tool for obtaining subseasonal environmental isotope records. Chem. Geol. 252, 21-30.

Dorado Liñán, I., Gutiérrez, E., Helle, G., Heinrich, I., Andreu-Hayles, L., Planells, O., Leuenberger, M., Bürger, C., Schleser, G., 2011. Pooled versus separate measurements of tree-ring stable isotopes. Sci. Total Environ. 409, 2244-2251.

Farquhar, G.D., O'Leary, M.H., Berry, J.A., 1982. On the relationship between carbon isotope - discrimination and the intercellular - carbon dioxide concentration in leaves. Aust. J. Plant Physiol. 9, 121-137.

Ferrio, J.P., Voltas, J., 2005. Carbon and oxygen isotope ratios in wood constituents of Pinus halepensis as indicators of precipitation, temperature and vapour pressure deficit. Tellus B 57, 164-173.

Gärtner, H., Nievergelt, D., 2010. The core-microtome: a new tool for surface preparation on cores and time series analysis of varying cell parameters. Dendrochronologia 28, 85-92.

Gaudinski, J.B., Dawson, T.E., Quideau, S., Schuur, E.A.G., Roden, J.S., Trumbore, S.E., Sandquist, D.R., Oh, S.-W., Wasylishen, R.E., 2005. Comparative analysis of cellulose preparation techniques for use with 13C, 14C, and 180 isotopic measurements. Anal. Chem. 77, 7212-7224.

Gessler, A., Brandes, E., Keitel, C., Boda, S., Kayler, Z.E., Granier, A., Barbour, M., Farquhar, G.D., Treydte, K., 2013. The oxygen isotope enrichment of leaf-exported assimilates-does it always reflect lamina leaf water enrichment? New Phytol. 200, 144-157.

Gori, Y., Wehrens, R., Greule, M., Keppler, F., Ziller, L., La Porta, N., Camin, F., 2013. Carbon, hydrogen and oxygen stable isotope ratios of whole wood, cellulose and lignin methoxyl groups of Picea abies as climate proxies. Rapid Commun. Mass Spectrom. 27, 265-275.

Green, J.W., 1963. Wood cellulose. Methods in Carbohydrate Chemistry III. Academic Press, New York.

Guest, D., Brown, J., 1997. Plant Defences Against Pathogens. Rockvale Publications for the Division of Botany, Rockvale Publications for the Division of Botany, School of Rural Science and Natural Resources. University of New England, Armidale New South Wales, New England, UK.

Harada, M., Watanabe, Y., Nakatsuka, T., Tazuru-Mizuno, S., Horikawa, Y., Sugiyama, J., Tsuda, T., Tagami, T., 2014. Alpha-cellulose extraction procedure for the tropical tree sungkai (Peronema canescens Jack) by using an improved vessel for reliable paleoclimate reconstruction. Geochem. J. 48, 299-307.

Harlow, B.A., Marshall, J.D., Robinson, A.P., 2006. A multi-species comparison of $\left({ }^{13} \mathrm{C}\right.$ from whole wood, extractive-free wood and holocellulose. Tree Physiol. 26, 767-774.

Harrington, K.J., Higgins, H.G., Michell, A.J., 1964. Infrared spectra of eucalyptus regnans F. Muell. and pinus radiata D. Don. Int. J. Biol. Chem. Phys. Technol. Wood 4 (Holzforschung).

Heinrich, I., Allen, K., 2013. Current issues and recent advances in australian dendrochronology: where to next? Geogr. Res. 51, 180-191.

Heinrich, I., Touchan, R., Dorado Liñán, I., Vos, H., Helle, G., 2013. Winter-to-spring temperature dynamics in Turkey derived from tree rings since AD 1125. Clim. Dyn. 41, 1685-1701.

Helle, G., Schleser, G.H., 2004. Beyond $\mathrm{CO}_{2}$-fixation by Rubisco - an interpretation of ${ }^{13} \mathrm{C} /{ }^{12} \mathrm{C}$ variations in tree rings from novel intra-seasonal studies on broad-leaf trees. Plant Cell Environ. 27, 367-380.

Hook, B.A., Halfar, J., Bollmann, J., Gedalof, Z. e., Rahman, Azizur, Reyes, M., Schulze, D.J., 2015. Extraction of $\alpha$-cellulose from mummified wood for stable isotopic analysis. Chem. Geol. 405, 19-27.

Hut, G., 1987. In: Report on the Consultants' Meeting on Stable Isotope Reference Sample for Geochemical and Hydrological Investigations. Vienna. (42 pp. pp.)

Isaac-Renton, M., Schneider, L., Treydte, K., 2016. Contamination risk of stable isotope samples during milling. Rapid Commun. Mass Spectrom. 30, 1513-1522.

Kürschner, K., Popik, M.G., 1962. Zur Analyse von Hölzern. Holzforschung 16, 1-11.

Kagawa, A., Sano, M., Nakatsuka, T., Ikeda, T., Kubo, S., 2015. An optimized method for stable isotope analysis of tree rings by extracting cellulose directly from crosssectional laths. Chem. Geol. 393-394, 16-25.

Kaye, G.W.C., Laby, T.H., 1973. Tables of physical and chemical constants. In: Pauling, L. (Ed.), The Nature of the Chemical Bond, 1960. Cornell University Press, London.

Konter, O., Holzkämper, S., Helle, G., Büntgen, U., Saurer, M., Esper, J., 2014. Climate sensitivity and parameter coherency in annually resolved $813 \mathrm{C}$ and 8180 from Pinus uncinata tree-ring data in the Spanish Pyrenees. Chem. Geol. 377, 12-19.

Kornexl, B.E., Gehre, M., Hofling, R., Werner, R.A., 1999. On-line delta O-18 
measurement of organic and inorganic substances. Rapid Commun. Mass Spectrom. $13,1685-1693$.

Koziet, J., 1997. Isotope ratio mass spectrometric method for the on-line determination of oxygen-18 in organic matter. J. Mass Spectrom. 32, 103-108.

Laumer, W., Andreu, L., Helle, G., Schleser, G.H., Wieloch, T., Wissel, H., 2009. A novel approach for the homogenization of cellulose to use micro-amounts for stable isotope analyses. Rapid Commun. Mass Spectrom. 23, 1934-1940.

Leavitt, S.W., Danzer, S.R., 1993. Method for batch processing small wood samples to holocellulose for stable-carbon isotope analysis. Anal. Chem. 65, 87-89.

Leavitt, S.W., 2010. Tree-ring CHO isotope variability and sampling. Sci. Total Environ. 408, 5244-5253.

Li, Z.-H., Labbé, N., Driese, S.G., Grissino-Mayer, H.D., 2011. Micro-scale analysis of treering $\delta^{18} \mathrm{O}$ and $\delta^{13} \mathrm{C}$ on $\alpha$-cellulose spline reveals high-resolution intra-annual climate variability and tropical cyclone activity. Chem. Geol. 284, 138-147.

Liang, W., Heinrich, I., Helle, G., Liñán, I.D., Heinken, T., 2013a. Applying CLSM to increment core surfaces for histometric analyses: a novel advance in quantitative wood anatomy. Dendrochronologia 31, 140-145.

Liang, W., Heinrich, I., Simard, S., Helle, G., Dorado Liñán, I., Heinken, T., 2013b. Climate signals derived from cell anatomy of Scots pine in NE-Germany. Tree Physiol. 33, 833-844.

Loader, N.J., Robertson, I., Barker, A.C., Switsur, V.R., Waterhouse, J.S., 1997. An improved technique for the batch processing of small wholewood samples to acellulose. Chem. Geol. 136, 313-317.

Loader, N.J., Robertson, I., Lücke, A., Helle, G., 2002. Preparation of hollocellulose from standard increment cores for stable carbon isotope analysis. Swansea Geogr. 37, 1-9.

Loader, N.J., Robertson, I., McCarroll, D., 2003. Comparison of stable carbon isotope ratios in the whole wood, cellulose and lignin of oak tree-rings. Palaeogeogr. Palaeoclimatol. Palaeoecol. 196, 395-407.

Loader, N.J., Helle, G., Los, S.O., Lehmkuhl, F., Schleser, G.H., 2010. Twentieth-century summer temperature variability in the southern Altai Mountains: a carbon and oxygen isotope study of tree-rings. Holocene 20, 1149-1156.

Loader, N.J., Young, G.H., McCarroll, D., Wilson, R.J., 2013. Quantifying uncertainty in isotope dendroclimatology. Holocene 2013. http://dx.doi.org/10.1177/ 0959683613486945.

Loader, N.J., Street-Perrott, F.A., Daley, T.J., Hughes, P.D.M., Kimak, A., Levanič, T., Mallon, G., Mauquoy, D., Robertson, I., Roland, T.P., van Bellen, S., Ziehmer, M.M., Leuenberger, M., 2014. Simultaneous determination of stable carbon, oxygen, and hydrogen isotopes in cellulose. Anal. Chem. 87, 376-380.

McCarroll, D., Loader, N.J., 2004. Stable isotopes in tree rings. Quat. Sci. Rev. 23, 771-801.

Nakatsuka, T., Zhang, C., Yasue, K., Kagawa, A., 2011. In: Extracting a-Cellulose From Tee-Ring Laths - A New Method for Tree Ring Stable Isotope Analysis. Xian, China 20-24 August 2011.

Pandey, K.K., Pitman, A.J., 2003. FTIR studies of the changes in wood chemistry following decay by brown-rot and white-rot fungi. Int. Biodeter. Biodegr. 52, $151-160$.

Pandey, K.K., Theagarajan, K.S., 1997. Analysis of wood surfaces and ground wood by diffuse reflectance (DRIFT) and photoacoustic (PAS) Fourier transform infrared spectroscopic techniques. Holz als Roh- und Werkstoff 55, 383-390.

Pettersen, R.C., 1984. The chemical composition of wood. Chem. Solid Wood 207, $57-126$.

Pritzkow, C., Heinrich, I., Grudd, H., Helle, G., 2014. Relationship between wood anatomy, tree-ring widths and wood density of Pinus sylvestris L. and climate at high latitudes in northern Sweden. Dendrochronologia 32, 295-302.

Richard, B., Quiles, F., Carteret, C., Brendel, O., 2014. Infrared spectroscopy and multivariate analysis to appraise alpha-cellulose extracted from wood for stable carbon isotope measurements. Chem. Geol. 381, 168-179.

Rinne, K.T., Boettger, T., Loader, N.J., Robertson, I., Switsur, V.R., Waterhouse, J.S., 2005. On the purification of $\alpha$-cellulose from resinous wood for stable isotope (H, C and O) analysis. Chem. Geol. 222, 75-82.

Robertson, I., Loader, N.J., Froyd, C.A., Zambatis, N., Whyte, I., Woodborne, S., 2006. The potential of the baobab (Adansonia digitata L.) as a proxy climate archive. Appl. Geochem. 21, 1674-1680.

Roden, J.S., Lin, G., Ehleringer, J.R., 2000. A mechanistic model for interpretation of hydrogen and oxygen isotope ratios in tree-ring cellulose. Geochim. Cosmochim. Acta 64, 21-35.

Saurer, M., Robertson, I., Siegwolf, R., Leuenberger, M., 1998. Oxygen isotope analysis of cellulose: an interlaboratory comparison. Anal. Chem. 70, 2074-2080.

Schmidt, H.L., Gleixner, G., Griffiths, H., 1998. Carbon isotope effects on key reactions in plant metabolism and 13C patterns in natural compounds. Stable Isotopes Integration of Biological, Ecological and Geochemical Processes, Environmental Plant Biology. BIOS Scientific Publishers, Oxford, UK.

Schmidt, H.L., Werner, R.A., Rossmann, A., 2001. O-18 pattern and biosynthesis of natural plant products. Phytochemistry 58, 9-32.

Schneider, L., Gärtner, H., 2013. The advantage of using a starch based non-Newtonian fluid to prepare micro sections. Dendrochronologia 31, 175-178.

Schollaen, K., Helle, G., 2013. Testing the influence of graphite and gypsum markings on stable isotope values $(\delta$. TRACE - Tree Rings in Archaeology, Climatology and Ecology. pp. 85-87 (Potsdam Germany).

Schollaen, K., Heinrich, I., Neuwirth, B., Krusic, P.J., D’Arrigo, R.D., Karyanto, O., Helle, G., 2013. Multiple tree-ring chronologies (ring width, $\delta^{13} \mathrm{C}$ and $\delta^{18} \mathrm{O}$ ) reveal dry and rainy season signals of rainfall in Indonesia. Quat. Sci. Rev. 73, 170-181.

Schollaen, K., Heinrich, I., Helle, G., 2014. UV-laser-based microscopic dissection of tree rings - a novel sampling tool for $\delta^{13} \mathrm{C}$ and $\delta^{18} \mathrm{O}$ studies. New Phytol. 201, 1045-1055.

Schollaen, K., Karamperidou, C., Krusic, P., Cook, E., Helle, G., 2015. ENSO flavors in a tree-ring $\delta^{18} \mathrm{O}$ record of Tectona grandis from Indonesia. Clim. Past 11, 1325-1333.

Schweingruber, F.H., 1996. Tree Rings and Environment: Dendroecology. Paul Haupt Publishers, Berne.

Sheu, D.D., Chiu, C.H., 1995. Evaluation of cellulose extraction procedures for stable carbon isotope measurement in tree ring cellulose. Int. J. Environ. Anal. Chem. 59, 59-67.

Simard, S., Morin, H., Krause, C., Buhay, W.M., Treydte, K., 2012. Tree-ring widths and isotopes of artificially defoliated balsam firs: a simulation of spruce budworm outbreaks in Eastern Canada. Environ. Exp. Bot. 81, 44-54.

Slotta, F., Riedel, F., Heußner, K.-U., Helle, G., 2014. In: The African Baobab - a Highresolution Archive for Climate Variability of Semi-arid Africa? Melbourne, Australia, 13-17 January 2014.

Slotta, F., Helle, G., Heußner, K.-U., Shemang, E., Riedel, F., 2017. Baobabs on Kubu Island, Botswana - A dendrochronological multi-parameter study using ring width and stable isotopes $\left(\delta^{13} \mathrm{C}, \delta^{18} \mathrm{O}\right)$. Erdkunde $71(1), 23-43$.

Szymczak, S., Joachimski, M.M., Bräuning, A., Hetzer, T., Kuhlemann, J., 2011. Comparison of whole wood and cellulose carbon and oxygen isotope series from Pinus nigra ssp. laricio (Corsica/France). Dendrochronologia 29, 219-226.

Szymczak, S., Joachimski, M.M., Bräuning, A., Hetzer, T., Kuhlemann, J., 2012. Are pooled tree ring $\delta^{13} \mathrm{C}$ and $\delta 180$ series reliable climate archives? - A case study of Pinus nigra spp. laricio (Corsica/France). Chem. Geol. 308-309 (40-49).

Szymczak, S., Hetzer, T., Bräuning, A., Joachimski, M.M., Leuschner, H.-H., Kuhlemann, J., 2014. Combining wood anatomy and stable isotope variations in a 600-year multiparameter climate reconstruction from Corsican black pine. Quat. Sci. Rev. 101, $146-158$.

Treydte, K.S., Schleser, G.H., Helle, G., Frank, D.C., Winiger, M., Haug, G.H., Esper, J., 2006. The twentieth century was the wettest period in northern Pakistan over the past millennium. Nature 440, 1179-1182.

Verheyden, A., Helle, G., Schleser, G.H., Dehairs, F., Beeckman, H., Koedam, N., 2004 Annual cyclicity in high-resolution stable carbon and oxygen isotope ratios in the wood of the mangrove tree Rhizophora mucronata. Plant Cell Environ. 27, 1525-1536.

Verheyden, A., Roggeman, M., Bouillon, S., Elskens, M., Beeckman, H., Koedam, N., 2005 Comparison between $\delta^{13} \mathrm{C}$ of $\alpha$-cellulose and bulk wood in the mangrove tree Rhizophora mucronata: Implications for dendrochemistry. Chem. Geol. 219, 275-282.

Werner, R.A., Brand, W.A., 2001. Referencing strategies and techniques in stable isotope ratio analysis. Rapid Commun. Mass Spectrom. 15, 501-519.

Wieloch, T., Helle, G., Heinrich, I., Voigt, M., Schyma, P., 2011. A novel device for batchwise isolation of a-cellulose from small-amount wholewood samples. Dendrochronologia 29, 115-117.

Williams, D.G., Coltrain, J.B., Lott, M., English, N.B., Ehleringer, J.R., 2005. Oxygen isotopes in cellulose identify source water for archaeological maize in the American Southwest. J. Archaeolog. Sci. 32, 931-939.

Woodborne, S., Hall, G., Robertson, I., Patrut, A., Rouault, M., Loader, N.J., Hofmeyr, M., 2015. A 1000-Year carbon isotope rainfall proxy record from south african baobab trees (Adansonia digitata L.). PLoS One 10, e0124202.

Wurster, C.M., Patterson, W.P., Cheatham, M.M., 1999. Advances in micromilling techniques: a new apparatus for acquiring high-resolution oxygen and carbon stable isotope values and major/minor elemental ratios from accretionary carbonate. Comput. Geosci. 25, 1159-1166.

Xu, C., Sano, M., Nakatsuka, T., 2011. Tree ring cellulose $\delta^{18} \mathrm{O}$ of Fokienia hodginsii in northern Laos: a promising proxy to reconstruct ENSO? J. Geophys. Res. 116, D24109. 